\title{
Radiological correlation of mechanism of intravascular migration of the ventriculoperitoneal shunt and technical considerations for endovascular retrieval
}

\author{
Rakesh K Varma $^{1 *}$, Karan Singh ${ }^{2}$, Theresa Caridi ${ }^{1}$, Aliaksei Salei ${ }^{1}$, Husameddin El Khudari ${ }^{1}$ \\ 1. Department of Radiology, University of Alabama at Birmingham, Birmingham, Alabama, USA \\ 2. Avalon University School of Medicine, Curacao
}

\begin{abstract}
* Correspondence: Rakesh K Varma, MD, FSIR, Division of Interventional Radiology, Department of Radiology, University of Alabama at Birmingham, 619 19th Street South, New Hillman Building, NHB-H623, Birmingham, 35249, AL, USA (入rvarma@uabmc.edu)
\end{abstract}

Radiology Case. 2022 Jan; 16(1):22-29 :: DOI: 10.3941/jrcr.v16i1.4346

\begin{abstract}
Migration of ventriculoperitoneal shunt into the pulmonary artery is a rare complication that can lead to shunt malfunction and cardiopulmonary complications. This case illustrates the significance of accidental transvenous placement of the shunt. Identification of the transvenous course of the catheter on cross sectional imaging can predict future catheter migration and also aid at surgical extraction. Formation of knot within the distal portion of the shunt catheter during migration or endovascular retrieval can occur, therefore measures to retrieve with knot and adhesions should be factored in before.
\end{abstract}

\section{CASE REPORT}

\section{CASE REPORT}

A 38-year-old woman with pseudotumor cerebri underwent placement of a right occipital ventriculoperitoneal (VP) shunt at an outside institution for blurry vision and severe headaches. Her symptoms resolved for a few months. However due to shunt malfunction, she underwent VP shunt revision with newly tunneled distal peritoneal shunt catheter (Fig. 1) with resolution of her symptoms. Incidental note of malpositioned distal end of the VP shunt in the right ventricle and bilateral pulmonary arteries was discovered when she underwent elective cholecystectomy approximately 2 years after the initial VP shunt placement (Fig. 2a).

The patient was then referred to our institution for management of the migrated VP shunt. On her presentation a few months later, she complained of blurry vision. Shunt series obtained at the time of presentation confirmed intrapulmonary artery migration with no shunt catheter within the abdomen but rather a coiled shunt within the chest, along the expected course of venous blood flow through the internal jugular vein, right brachiocephalic vein, superior vena cava, through the heart and into the pulmonary arteries (Fig. 2b). The intrajugular course of the catheter (Fig. 3a, 3b) was confirmed by computer tomographic angiography (CTA) of the neck and chest showing the distal portion of the catheter coiled in the pulmonary arteries with associated thrombus. The patient underwent revision with neurosurgery including placement of a newly tunneled distal peritoneal shunt catheter with laparoscopic assistance. The distal migrated portion of the existing catheter within the intravascular segment could not be retrieved surgically as the distal catheter was adhered to the pulmonary arteries causing frequent premature ventricular contractions and occasional bigeminy during forced traction. The retrieved portion during 
surgery was cut. The remaining portion of the VP shunt extended from the right ventricle to bilateral main pulmonary arteries. Interventional radiology was consulted to attempt removal of the remainder of the catheter to avoid open cardiac surgery.

A right common femoral vein (CFV) access was established and a 12 French $40 \mathrm{~cm}$ sheath was placed over an Amplatz wire. A 30mm Amplatz goose neck snare (Medtronic) was then advanced into the right ventricle to snare the catheter fragment. Given the distal most coiled segment of the catheter was adhered to the pulmonary arteries, the remainder of the catheter fractured and was removed in piece meal. There was no visible knot on fluoroscopy and planning CT, but as the catheter was retrieved there was formation of a knot due to redundancy of the catheter and its coiling. The $12 \mathrm{Fr}$ sheath was then exchanged for a 16 Fr sheath and the catheter was again snared and was freed from the adhesion with the pulmonary artery with slowly graded traction, just enough to prevent the catheter to break. Since the knot diameter was larger than the sheath diameter (Fig. 4), the sheath and the knot were removed together through the right $\mathrm{CFV}$ venotomy site and hemostasis at the venotomy site was achieved by manual compression. There was complete resolution of arrhythmias after complete retrieval of the migrated intrapulmonary artery shunt. Her hospital course was uneventful and was discharged on postoperative day 2 .

\section{DISCUSSION}

\section{Etiology \& Demographics:}

VP shunts are placed routinely by neurosurgeons in children and adults, most often for cerebrospinal fluid (CSF) diversion in the setting of hydrocephalus [1,2]. Complications associated with CSF shunt are commonly related to the catheter and include catheter infection, mechanical failure including occlusion of the distal catheter tip, kinking or fracture, and migration. Reported mechanical shunt complication is roughly 1 in 1000 patients who have undergone a shunt procedure [3]. Migration of the shunt catheter has been reported to gastrointestinal tract $(35 \%)$, urinary bladder and perineum (4\%), scrotum (14\%), abdominal wall (14\%), intracranial/subgaleal (11\%), chest/thoracic migration $(8 \%)$ with even rarer locations like intracardiac/intravascular (7\%). Miscellaneous sites (4\%) including liver, gallbladder, lower limbs have been also reported [3]. According to a meta-analysis by $\mathrm{L} \mathrm{S}$ Harischandra et al, migration is more common in pediatric age group (71.2\%) as compared to adults (28.8\%) [3]. Factors like excessive peristaltic activity and weaker bowel wall contributing to increased catheter migration into the bowel, patent processus vaginalis contributing to migration into the scrotum and weaker abdominal wall have been suggested for increase in catheter migration in children [3]. VP shunt catheter migration into the pulmonary artery is a rare complication with only 15 published cases to date [4]. The proposed mechanism is the accidental transvenous tunneling at the level of the neck, when the catheter courses form a posterior VP shunt chamber to the anterior chest wall. The intravascular course within the jugular vein predisposes the catheter to continuous suction by negative inspiratory pressure leading to gradual intravascular migration. Majority of reported cases were also not associated with profuse bleeding while tunneling thus suggesting a retrospective diagnosis [4].

\section{Clinical \& Imaging findings:}

Shunt migration can present with symptoms related to the site of migration or shunt dysfunction. Caudal migration (downward) is more common with incidence around $10 \%$ as compared to cranial migration (upward). Caudal migrations are usually asymptomatic versus cranial which are usually symptomatic. Approximately $50 \%$ of the cases are discovered incidentally [4]. Intravascular migration can lead to serious complications including arrhythmias and pulmonary embolism [3]. The latency between the shunt placement to the diagnosis of migration has been reported from 5 days to 4 years [3]. The proposed mechanism for intravascular migration is the unrecognized course of the shunt catheter while tunneling posterior to anterior in the neck, as seen in our case. The intravascular catheter is then subjected to constant suction by the negative intrathoracic pressure and by the venous flow pushing the catheter towards the heart and distally. Additionally chronic erosion into the vessels in close proximity has been proposed. On routine imaging careful evaluation of the course of the ventriculoperitoneal shunt, especially in the neck, should be performed to assess for possible intravascular course which can predict future intravascular migration. Identifying the site of intravascular entry also aids during surgical removal. Additionally the distal end of the catheter can be associated with knot formation and pulmonary embolism and hence retrieval should be performed under echocardiographic or fluoroscopic monitoring [5].

\section{Treatment \& Prognosis:}

Occasionally the physical removal of the distal embolized fragment, both surgically or endovascularly, can be complicated by knotting of the distal end of the VP shunt and adhesions to the surrounding vessel wall [6]. Also adhesion to the pulmonary artery or the heart valves can result in undue traction during retrieval provoking arrhythmia as seen in our case. The initial approach to removal would be to identify the point of transvenous entry point on imaging and to expose the catheter at the entry point followed by extraction under fluoroscopy and electrographic monitoring. If the knot prevents from complete retrieval, a venotomy could be performed to free the knot. Alternatively, the embolized intravascular fragment after partial surgical removal can be retrieved through an endovascular approach. Though endovascular removal of the embolized VP shunt has been described, there are only 6 reports in literature [5]. Using a larger sheath diameter > 16 Fr can help encase the knot and the use of slow and graded traction can free the adhesions of the catheter to the surrounding vasculature. Similar to surgical extraction, monitoring of the blood pressure, heart rate, cardiac rhythm and clinical symptoms is important. The removal of migrated VP shunt usually requires a multidisciplinary approach including a neurosurgeon, interventional radiologist, vascular surgeon and cardiothoracic surgeon. Thoracotomy should be considered as the last option and as back up during surgical or endovascular retrieval. 


\section{CONCLUSION}

Intrapulmonary migration of the VP shunt is a rare complication. Being aware of transvenous tunneling can reduce the risk of intravascular migration and shunt complications. Identifying the site of transvenous entry of the shunt can aid at surgical removal. Knots within the migrated fragment may occur during retrieval and such possibility should be factored in while considering endovascular retrieval of the migrated distal catheter. Having a multidisciplinary approach is required for successful and safe retrieval.

\section{TEACHING POINT}

Accidental transvenous tunneling through the neck veins can result in intravascular migration of the VP shunt which can eventually lead to shunt malfunction, cardiac arrhythmias and pulmonary embolism. Awareness of the mechanism of intravascular migration can help radiologists in identifying the transvenous course of the catheter on routine imaging of the neck, allowing prospective diagnosis before the migration occurs.

\section{REFERENCES}

1. Fowler JB, De Jesus O, Mesfin FB. Ventriculoperitoneal Shunt. [Updated 2021 Feb 7]. In: StatPearls [Internet]. Treasure Island (FL): StatPearls Publishing; 2021 Jan-. Available from: https://www.ncbi.nlm.nih.gov/books/NBK459351

2. Rymarczuk GN, Keating RF, Coughlin DJ, Felbaum D, Myseros JS, Oluigbo C, Yadav B, Sharma K, Magge SN. A Comparison of Ventriculoperitoneal and Ventriculoatrial Shunts in a Population of 544 Consecutive Pediatric Patients. Neurosurgery. 2020 Jul 1;87(1):80-85. doi: 10.1093/neuros/nyz387. Erratum in: Neurosurgery. $2020 \mathrm{Feb}$ 1;86(2):315. PMID: 31586189

3. Harischandra LS, Sharma A, Chatterjee S. Shunt migration in ventriculoperitoneal shunting: A comprehensive review of literature. Neurol India. 2019 Jan-Feb;67(1):85-99. doi: 10.4103/0028-3886.253968. PMID: 30860103

4. Li W, Li Y, Sun Y, Chen L. Migration of a Distal Ventriculoperitoneal Shunt Catheter Into the Pulmonary Vasculature: a Report of an Unusual Case and a Review of the Literature. J Craniofac Surg. 2019 May/Jun;30(3):e243-e244. doi: 10.1097/SCS.0000000000005255. PMID: 31048620

5. Carrasco R, Pascual JM. On heart migration of the peritoneal catheter. Neurochirurgie. 2015 Oct;61(5):301-3. doi: 10.1016/j.neuchi.2015.07.001. Epub 2015 Oct 1. PMID: 26428865

6. Frahm-Jensen G, Newton PR, Drummond KJ, Wagner TP, Mees BM. Intracardiac migration and knotting of a ventriculoperitoneal shunt. J Clin Neurosci. 2015 Apr;22(4):771-3. doi: 10.1016/j.jocn.2014.10.020. Epub 2015 Feb 20. PMID: 25709057 


\section{FIGURES}

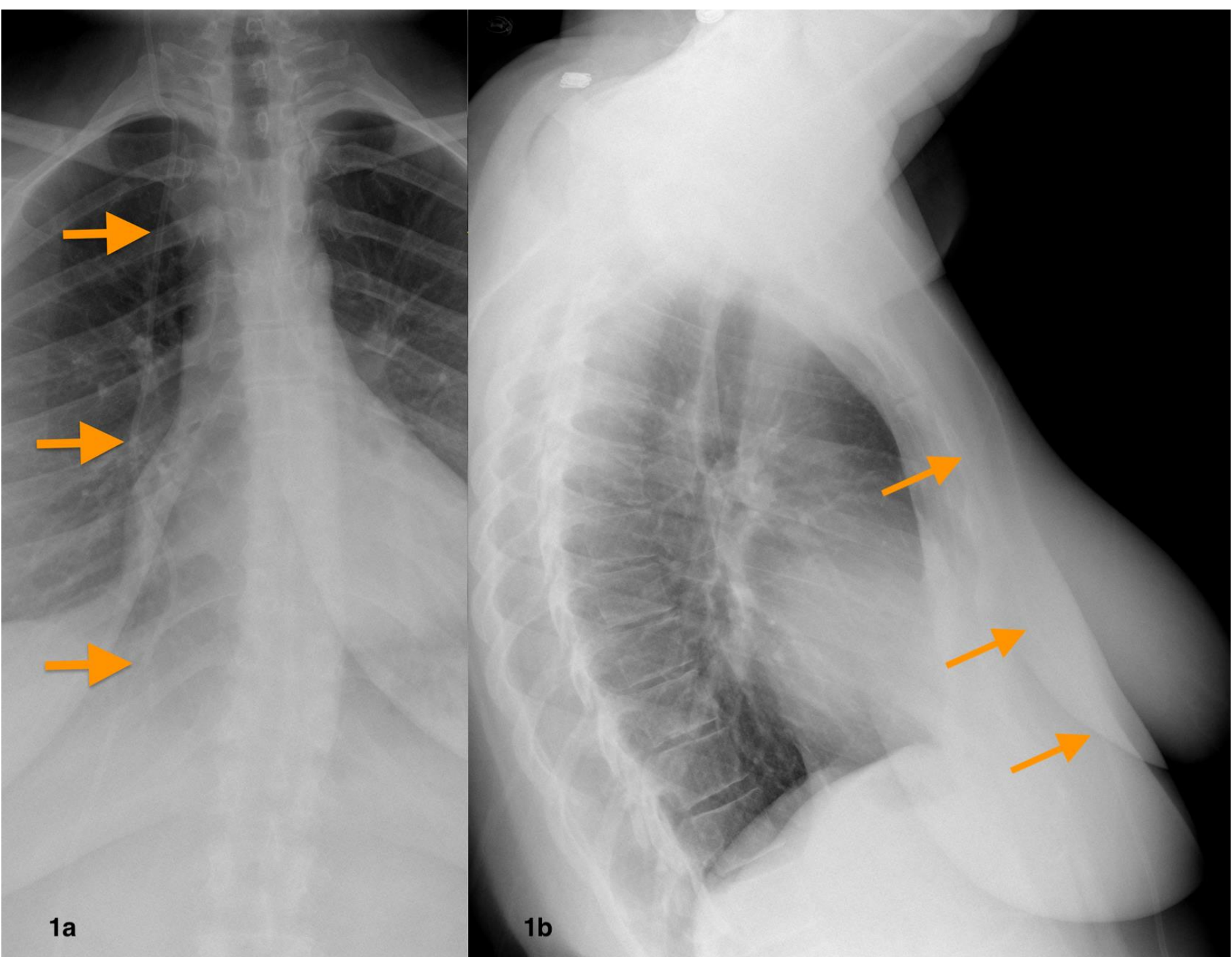

Figure 1: 38-year-old female with history of pseudotumor cerebri status post VP shunt creation in 2016 with revision in 2017.

FINDINGS: The posteroanterior (1a) and lateral (1b) chest radiograph performed soon after the VP shunt revision in 2017 depicts an expected course of the VP catheter (arrows), which extends from the patients neck towards the abdomen.

TECHNIQUE: Philips DigitalDiagnost 


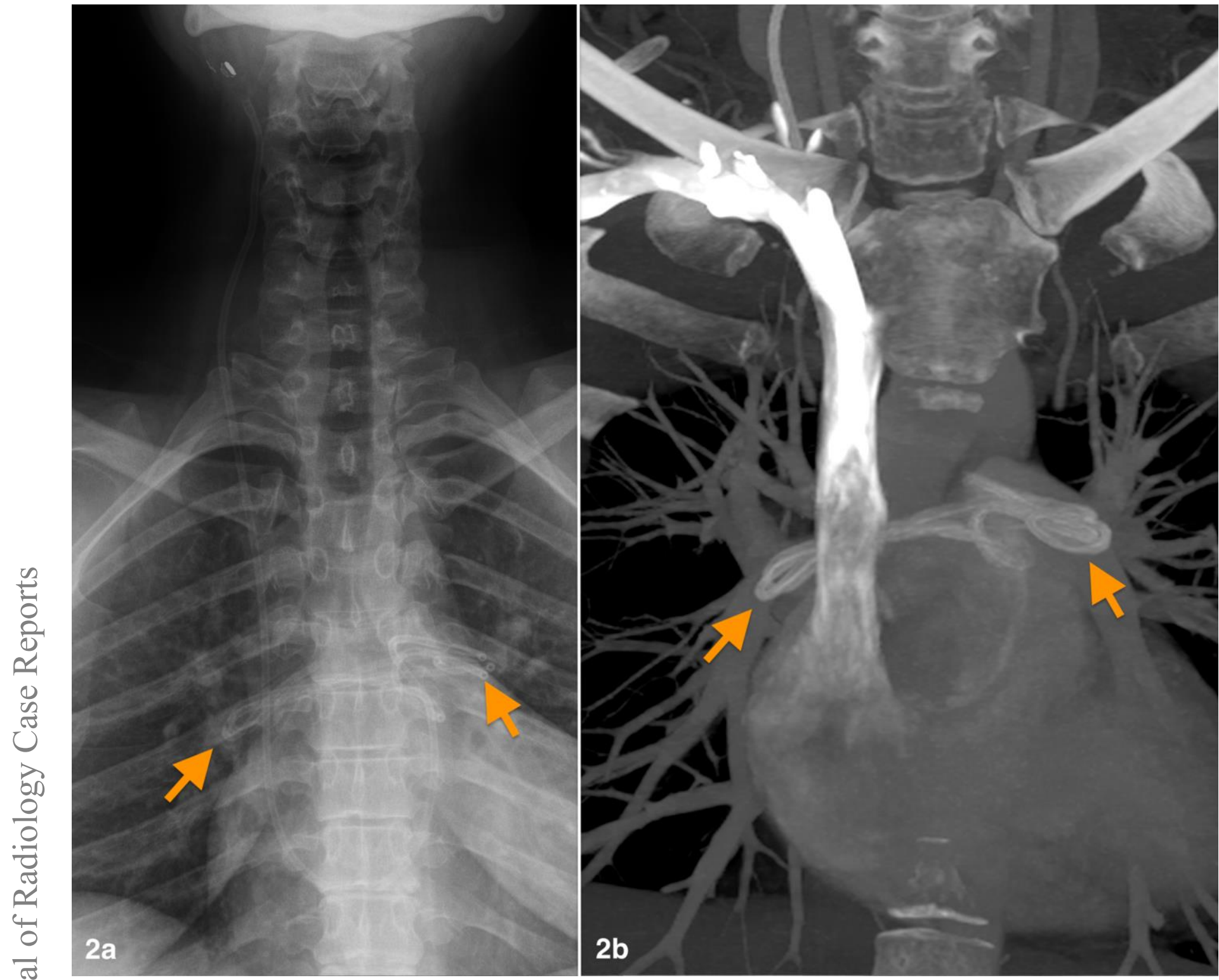

Figure 2: 38-year-old female with history of pseudotumor cerebri status post VP shunt creation in 2016 with revision in 2017.

FINDINGS: PA chest radiograph (Figure 2a) as well as contrast enhanced coronal maximum intensity projection (MIP) reconstruction of the computed tomography (CT) of the chest (Figure 2b), both performed upon admission in March 2019, demonstrate intravascular migration of the shunt catheter with the distal portion of the VP shunt catheter (arrows) within bilateral pulmonary arteries.

TECHNIQUE: Figure 2a: Philips DigitalDiagnost; Figure 2b: Philips Brilliance 64, 125mL IV Omnipaque 350, kVp 140, mA 396. 


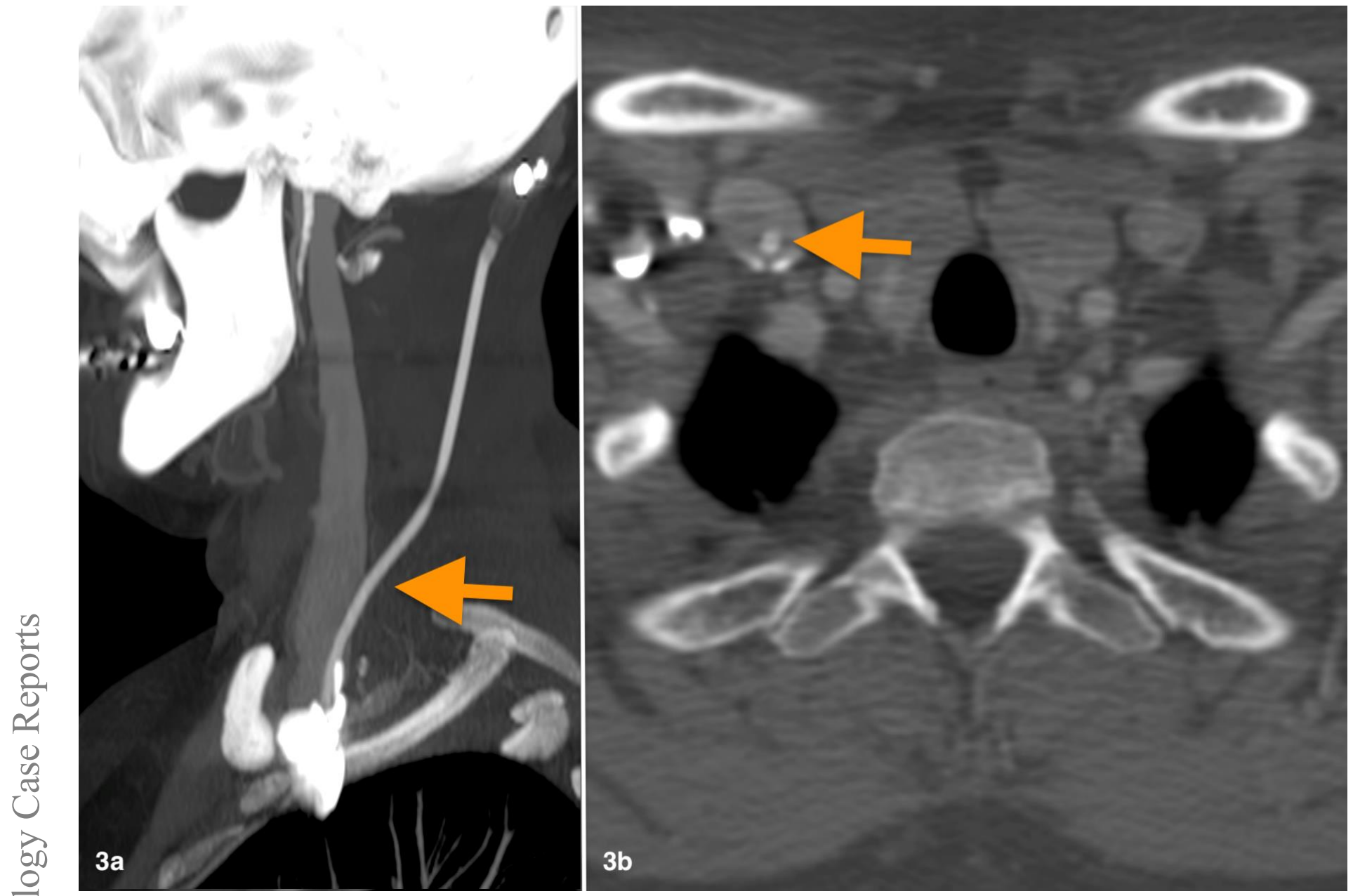

Figure 3: 38-year-old female with history of pseudotumor cerebri status post VP shunt creation in 2016 with revision in 2017.

FINDINGS: Sagittal MIP (Figure 3a) and axial (Figure 3b) contrast enhanced CT images of the neck, performed upon admission in March 2019, demonstrate intrajugular course of the VP shunt catheter (arrows) resulting from inadvertent transvenous tunneling of the catheter during VP shunt revision.

TECHNIQUE: Philips Brilliance 64, 125mL IV Omnipaque 350, kVp 140, mA 396. 


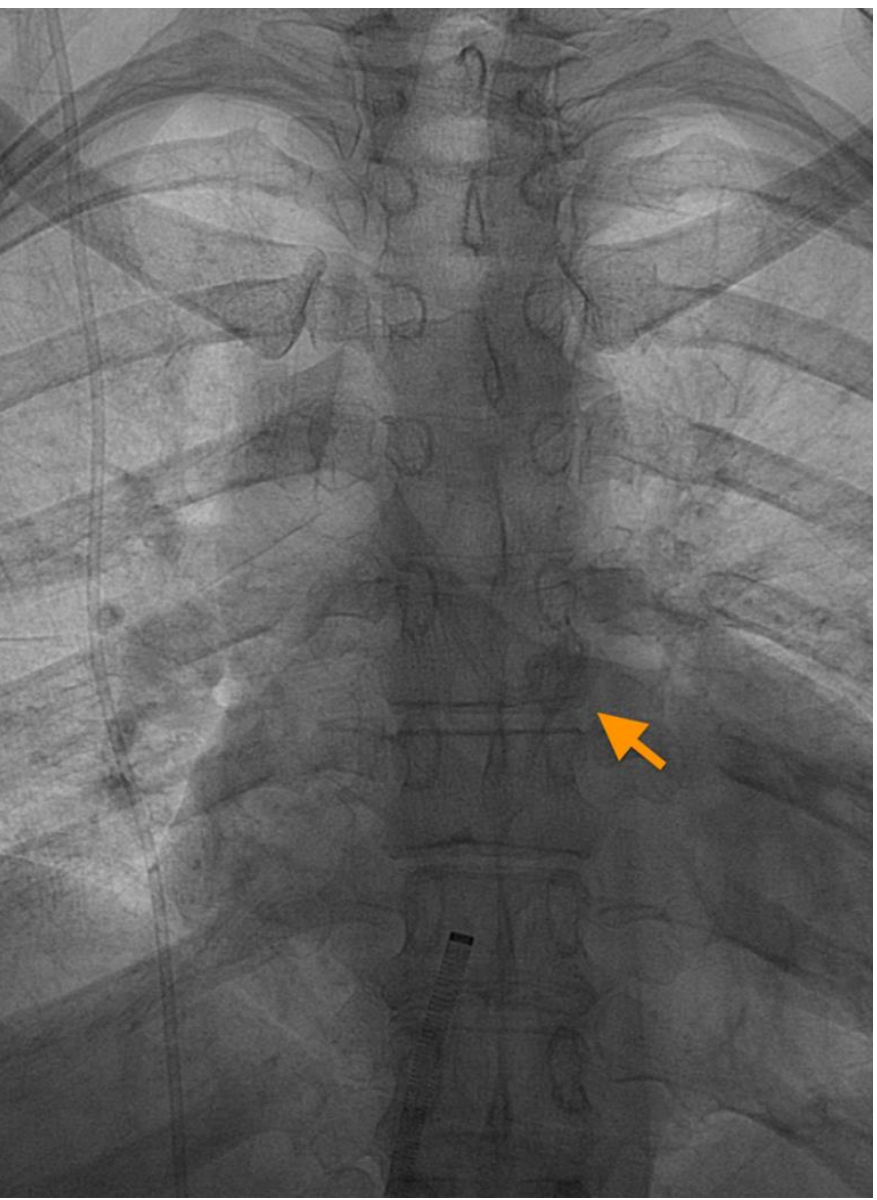

Figure 4 (left): 38-year-old female with history of pseudotumor cerebri status post VP shunt creation in 2016 with revision in 2017.

FINDINGS: Fluoroscopic image of the chest obtained during retrieval of the migrated VP shunt catheter illustrating knot formation. An arrow points at a knot formed during the VP shunt catheter retrieval.

TECHNIQUE: Philips Allura Xper

\begin{tabular}{|c|c|}
\hline Etiology & $\begin{array}{l}\text { - Iatrogenic: accidental transvenous tunneling at the level of the neck during placement of the } \\
\text { ventriculoperitoneal shunt. The intravascular course within the jugular vein (internal or external) } \\
\text { predisposes the catheter to continuous suction by negative inspiratory pressure leading to gradual } \\
\text { intravascular migration. } \\
\text { - Trauma: Chronic erosion into the vessels in closed proximity due to routine extension and flexion of } \\
\text { the neck. }\end{array}$ \\
\hline Incidence & - $7 \%$ of reported ventriculoperitoneal shunt migration \\
\hline Gender predilection & - No gender predilection \\
\hline Age predilection & - More common in pediatric age group $(71.2 \%)$ \\
\hline Risk factors & $\begin{array}{l}\text { - } \mathrm{BMI}>30 \mathrm{~kg} / \mathrm{m}^{2} \\
\text { - Previous shunt procedure/surgery } \\
\text { - Negative intrathoracic pressure e.g. COPD }\end{array}$ \\
\hline Treatment & $\begin{array}{l}\text { - Surgical intervention: removal of the distal catheter from the heart followed by its repositioning into } \\
\text { the peritoneum or its conversion into a ventriculoatrial (VA) shunt. Venotomy may be necessary to } \\
\text { remove the catheter if catheter is adherent to the Internal Jugular vein (IJV) at its point of entry into } \\
\text { the vascular compartment. } \\
\text { - Endovascular intervention: if the catheter is entangled with a valve or cannot be pulled out easily }\end{array}$ \\
\hline Prognosis & - If not treated, might lead to catheter malfunction, cardiac arrhythmia, or thrombosis. \\
\hline Findings on imaging & $\begin{array}{l}\text { - Abnormal ventriculoperitoneal shunt course (intracardiac/intravascular). } \\
\text { - Site of intravascular entry might be identified on cross-sectional imaging. } \\
\text { - Distal tip of the shunt might be associated with knot or thrombus formation } \\
\text { - Adhesion of the distal tip to adjacent vessel wall or heart valve }\end{array}$ \\
\hline
\end{tabular}

Table 1: Summary table of intravascular migration of ventriculoperitoneal (VP) shunt. 


\begin{tabular}{|c|c|c|c|}
\hline Differential Diagnosis & Clinical & Radiographs & CT \\
\hline $\begin{array}{l}\text { Intravascular migration } \\
\text { of the VP shunt }\end{array}$ & $\begin{array}{l}\text { - H/O VP shunt surgery } \\
\text { - Shunt dysfunction } \\
\text { - Cardiac arrhythmias } \\
\text { - Pulmonary embolism } \\
\text { - Asymptomatic }\end{array}$ & $\begin{array}{l}\text { - Abnormal course of } \\
\text { VP shunt. } \\
\text { - Shunt tip terminating } \\
\text { in the right heart or } \\
\text { pulmonary artery }\end{array}$ & $\begin{array}{l}\text { - Abnormal course } \\
\text { - The distal part of the shunt within } \\
\text { intravascular/intracardiac compartment. } \\
\text { - Distal tip of the shunt might be associated } \\
\text { with knot or thrombus formation. } \\
\text { - Adhesion of the distal tip to adjacent } \\
\text { vessel wall or heart valve. }\end{array}$ \\
\hline \multicolumn{4}{|l|}{$\begin{array}{l}\text { Non-vascular migration } \\
\text { of the VP shunt: }\end{array}$} \\
\hline $\begin{array}{l}\text { Subcutaneous/ } \\
\text { subgaleal migration }\end{array}$ & $\begin{array}{l}\text { - Subcutaneous/ } \\
\text { - subgaleal swelling } \\
\text { - Tense, wide fontanels } \\
\text { - Persistent vomiting }\end{array}$ & $\begin{array}{l}\text { - Looping of the catheter } \\
\text { inside subcutaneous } \\
\text { tissues }\end{array}$ & $\begin{array}{l}\text { - Abnormal course of VP shunt } \\
\text { (subcutaneous/subgaleal) } \\
\text { - The distal part of the shunt within } \\
\text { subcutaneous/subgaleal space } \\
\text { - Hydrocephalus }\end{array}$ \\
\hline Scrotal migration & $\begin{array}{l}\text { - Scrotal pain and } \\
\text { swelling } \\
\text { - Development of } \\
\text { scrotal hydrocele } \\
\text { - Malfunctioning shunt }\end{array}$ & $\begin{array}{l}\text { - Distal tip terminating } \\
\text { in the scrotum }\end{array}$ & $\begin{array}{l}\text { - Abnormal course of VP shunt (scrotal) } \\
\text { - The distal part of the shunt within the } \\
\text { scrotum } \\
\text { - Hydrocele }\end{array}$ \\
\hline Vaginal migration & $\begin{array}{l}\text { - Catheter protruding } \\
\text { through the vagina } \\
\text { - Vaginal leak }\end{array}$ & $\begin{array}{l}\text { - Abnormal catheter } \\
\text { course through the } \\
\text { vagina }\end{array}$ & $\begin{array}{l}\text { - Abnormal course of VP shunt (through } \\
\text { the vagina) } \\
\text { - The distal part of the shunt within vagina }\end{array}$ \\
\hline Gastric migration & - Abdominal pain & $\begin{array}{l}\text { - Abnormal catheter } \\
\text { course within the } \\
\text { stomach }\end{array}$ & $\begin{array}{l}\text { - Abnormal course of VP shunt (through } \\
\text { the stomach wall) } \\
\text { - The distal part within the gastric lumen } \\
\text { - Abnormal course of VP shunt (through } \\
\text { the bowel wall) }\end{array}$ \\
\hline Bowel migration & - Abdominal pain & $\begin{array}{l}\text { - Abnormal catheter } \\
\text { course within the } \\
\text { bowel }\end{array}$ & $\begin{array}{l}\text { - The distal part of the shunt within the } \\
\text { bowel }\end{array}$ \\
\hline Hepatic migration & - Abdominal pain & $\begin{array}{l}\text { - Abnormal catheter tip } \\
\text { course within the liver } \\
\text { parenchyma }\end{array}$ & $\begin{array}{l}\text { - Abnormal course of VP shunt tip (through } \\
\text { the liver parenchyma) } \\
\text { - The distal tip of the shunt within the liver } \\
\text { parenchyma }\end{array}$ \\
\hline $\begin{array}{l}\text { Extra-abdominal } \\
\text { migration (skin } \\
\text { perforation) }\end{array}$ & $\begin{array}{l}\text { - Localized pain } \\
\text { - Catheter protrusion } \\
\text { through the skin }\end{array}$ & $\begin{array}{l}\text { - Abnormal catheter } \\
\text { course with protrusion } \\
\text { of the catheter tip } \\
\text { through the skin }\end{array}$ & $\begin{array}{l}\text { - Abnormal course of VP shunt tip (through } \\
\text { the skin) } \\
\text { - The distal tip of the shunt protruding } \\
\text { through the skin }\end{array}$ \\
\hline
\end{tabular}

Table 2: Differential diagnosis table for intravascular migration of ventriculoperitoneal (VP) shunt.

\section{ABBREVIATIONS}

$\mathrm{CSF}=$ Cerebrospinal fluid

$\mathrm{CT}=$ Computed tomography

CTA $=$ Computer tomographic angiography

$\mathrm{CFV}=$ Common femoral vein

$\mathrm{Fr}=$ French

MIP = Maximum intensity projection

$\mathrm{VP}=$ Ventriculoperitoneal

\section{KEYWORDS}

Ventriculoperitoneal shunt; intravascular tunneling; intrapulmonary migration; endovascular retrieval; interventional radiology

\section{Online access}

This publication is online available at: www.radiologycases.com/index.php/radiologycases/article/view/4346

\section{Peer discussion}

Discuss this manuscript in our protected discussion forum at: www.radiolopolis.com/forums/JRCR

\section{Interactivity}

This publication is available as an interactive article with scroll, window/level, magnify and more features.

Available online at www.RadiologyCases.com

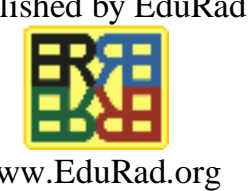

